\title{
Ecological network analysis of embodied particulate matter 2.5 - A case study of Beijing
}

\author{
Siyuan Yang ${ }^{a}$, Brian Fath ${ }^{\mathrm{b}, \mathrm{c}}$, Bin Chen ${ }^{\mathrm{a}, *}$ \\ ${ }^{a}$ School of Environment, Beijing Normal University, Beijing 100875, China \\ ${ }^{\mathrm{b}}$ Department of Biological Sciences, Towson University, Towson, MD 21252, USA \\ ${ }^{\mathrm{c}}$ Dynamic Systems, International Institute for Applied Systems Analysis, Laxenburg, Austria
}

\section{H I G H L I G H T S}

- A $\mathrm{PM}_{2.5}$ emission inventory framework on sectoral scale is constructed.

- The proportion of direct and indirect $\mathrm{PM}_{2.5}$ emissions is $2: 1$.

- Sectors related to industry are the dominant controller of embodied emission network.

\section{A R T I C L E I N F O}

\section{Article history:}

Received 18 February 2016

Received in revised form 4 April 2016

Accepted 16 April 2016

Available online $\mathrm{xxxx}$

\section{Keywords:}

Air pollution

Ecological network analysis

Input-output analysis

Embodied emissions

Energy structure

\begin{abstract}
A B S T R A C T
Over the past decades, China has been facing severe airborne pollution associated with atmospheric fine particulate matter $\left(\mathrm{PM}_{2.5}\right)$. Much attention has been paid to the physical transport of $\mathrm{PM}_{2.5}$ emissions. However, the embodied emissions, namely the emissions transferred through economic activities, have seldom been investigated. In this paper, embodied emission of $\mathrm{PM}_{2.5}$ from each sector of Beijing is quantified based on input-output analysis (IOA). Forty-two economic sectors from the input-output table are aggregated into fifteen components. Furthermore, the mutual interactions and control relationship within those sectors have been revealed by using ecological network analysis (ENA) to identify the dominant sectors. The results show that, in $2010,34 \%$ of the total $\mathrm{PM}_{2.5}$ emissions, or $59.4 \mathrm{kt} \mathrm{PM}_{2.5}$, were indirect emissions traded through economic sectors within Beijing. According to the results of ENA, we found that "Smelting \& Pressing of Metals", "Metal Products" and "Nonmetal Mineral Products" are the top three sectors with the highest control levels while "Agriculture", "Catering Services" and "Residential Services" are the lowest-ranking sectors among the system. The network confirms that sectors related to heavy industry are the dominant sectors driving the embodied $\mathrm{PM}_{2.5}$ emissions in the whole system. Compared to the conventional approaches for tracking $\mathrm{PM}_{2.5}$ emissions, ENA may provide a practical way to reveal the mechanisms of embodied $\mathrm{PM}_{2.5}$ emission flows via socioeconomic activities from a holistic perspective.
\end{abstract}

(c) 2016 Published by Elsevier Ltd.

\section{Introduction}

Socioeconomic activities heavily dependent on fossil fuel energy sources are coupled with an adverse effect on air quality conditions in China [1,2]. In 2012, nearly 90\% of China's total primary energy came from coal and petroleum, which are considered as major air pollution sources [3,4]. In addition, various socioeconomic activities can exert negative impact on air quality [5]. It is necessary to reveal the mechanisms of how socioeconomic activi-

\footnotetext{
* Corresponding author at: No. 19, Xinjiekouwai St., Beijing 100875, China. E-mail address: chenb@bnu.edu.cn (B. Chen).
}

ties affect $\mathrm{PM}_{2.5}$ emissions and to explore efficient and stable management of mitigating emissions.

The reduction of $\mathrm{PM}_{2.5}$ emissions relies on the identification of the pollution source. Previous studies on source apportionment of airborne particulate matter are largely related to chemical pathways and technology-based approach, which refer to the term "production-based emission accounting". Experiments were conducted by taking $\mathrm{PM}_{2.5}$ samples from multiple sites and quantitatively apportion the sources that contribute to fine particle mass concentrations [6,7]; The technology-based inventories were established based on calculating the particulate emissions from the combination of energy statistics, technology distributions and emissions factors $[8,9]$. These researches effectively trace the 
$\mathrm{PM}_{2.5}$ emissions back to the sources where particles were physically generated and provide practical suggestions to direct the implementation of emission abatement. For example, the results of Beijing from production-based perspective show that the major direct contributors to $\mathrm{PM}_{2.5}$ pollution are industrial process, vehicle exhaust, soil dust, and fuel combustion $[6,10]$.

However, production-based emission accounting lacks an understanding of the socioeconomic drivers of $\mathrm{PM}_{2.5}$ emissions when exploring emission mitigation strategies [11]. A consumption-based accounting, which can assign emissions to final consumers of commodities by examining the supply chain, provides fundamentally different information [12]. Several studies have already been demonstrated for smog-forming airborne pollutants from a consumption-based perspective. Streets et al. [13] estimated the trade-related air pollutant emissions and found that $10-40 \%$ of emissions in China's Pearl River Delta were caused by export-related activities. Yang et al. focused on trans-boundary air pollution emissions through transactions between Jing-Jin-Ji district and the rest of China and traced the transfer route of embodied particles within the district [14]. Zhao et al. [15] quantified virtual air pollutants through interprovincial trade in China based on a consumption-based emission framework. Guan et al. [11] analyzed production-related $\mathrm{PM}_{2.5}$ emission changes in China between 1997 and 2010 to identify the socioeconomic drivers of primary $\mathrm{PM}_{2.5}$ emissions from a consumption perspective. The disparity between production- and consumption-based emissions inventories in China were also explored in the context of international trade $[16,17]$. Others borrowed the concept of "embodied emission" from energy analysis to calculate the emissions embodied in products or services which are traded nationally or globally $[18,19]$. In general, there are two types of approaches adopted to quantify the embodied emissions: the bottom-up and top-down accounting approaches. The former method is based on the process analysis which collects detailed process data to calculate embodied emissions generated in economic activities. It can be used to assess the impact of the entire life cycle of each individual product on the environment [20]. For instance, emissions embodied in the electricity supply includes those airborne pollutants directly discharged in the power plant plus all the emissions discharged indirectly due to producing other inputs to the power plant, like vehicles, metal processing, building construction, and coal mining [21]. However, the bottom-up approach cannot distribute the responsibility to the intermediate and final consumers, let alone identify driving forces [22,23]. The top-down approach is based on input-output analysis (IOA) which describes the material flow through economic sectors in order to identify how much PM emissions are embodied in producing a specific product [24-27]. The basic foundation of this method based on an input-output table of the economic structure which shows the complex interregional or inter-sectoral relationships based on monetary flow $[28,29]$. Some studies have explored the embodied $\mathrm{PM}_{2.5}$ emissions flows via domestic or foreign supply chains on regional or national scale $[30,31]$. By using this approach, all PM intensive transactions within economic sectors can be identified and captured [32-34].

Nevertheless, few have paid attentions to the systematic configuration of virtual material flows [35], which should be further explored to illustrate the inner interactions and linkages of $\mathrm{PM}_{2.5}$ emissions within the socioeconomic system. For this reason, ecological network analysis (ENA), which was first developed by Hannon [36] to analyze the interdependence of each member of an ecosystem upon the others and trace the distribution of both direct and indirect element flows in an ecosystem [37,38], is adopted in this study to investigate the network structure of the embodied $\mathrm{PM}_{2.5}$ emission flows. The network control analysis (NCA) derived from ENA is used to investigate the control relationship and interdependence between sectors by quantifying the contribution of each sector to the others' inputs and outputs [39-42]. The cumulative pathways of emission flows can also be highlighted based on the allocation of integral control $[43,44]$. Considering the specific local conditions (e.g., energy structure, industry specification, and economic activities), the internal structure analysis of embodied $\mathrm{PM}_{2.5}$ emissions via the economic sectors may therefore provide a different perspective to understand the fundamental factors that drive the emission flows within concerned areas [45].

In this study, a $\mathrm{PM}_{2.5}$ emission inventory framework on the sectoral scale is constructed based on an economic input-output model, which is used to parcel out major exchange pathways into small pieces between sectors and distribute $\mathrm{PM}_{2.5}$ emissions to sectors according to where products or services are finally consumed. The $\mathrm{PM}_{2.5}$ emissions embodied in economic activities between fifteen sectors in Beijing are quantified accordingly. Then, the embodied $\mathrm{PM}_{2.5}$ emission network is configured by ENA to examine the structure and function of each sector and quantify the distribution of control level through the interactions among sectors. Thus, IOA and ENA can be combined to investigate the direct and indirect $\mathrm{PM}_{2.5}$ emissions and identify the dominant sectors as well as their linkages.

This paper is organized as follows. In Section 2, the methodologies of IOA and ENA are briefly described. Section 3 quantifies direct and indirect $\mathrm{PM}_{2.5}$ emissions and presents the control analysis based on ENA. Finally, a range of results and policy implications are addressed.

\section{Materials and methods}

\subsection{Study site and data}

Beijing lies in the north-east of China, which is surrounded on three sides by mountains. The mountainous area has an average elevation of over $1000 \mathrm{~m}$ and the urban area of Beijing comprises lowlands of $30-50 \mathrm{~m}$ above sea level. Within the administrative boundary of Beijing, $63 \%$ of the area is hilly or mountainous region. Its special terrain makes it difficult to disperse the air pollution. Although coal combustion has been prohibited in urban areas except for permitted high capacity boilers with effective emission control system, residential cooking and space heating in both the rural area and suburban area (92\% of total area) of Beijing still relied largely on coal combustion (especially coal briquettes) [46]. In 2010, the average concentration level of daily $\mathrm{PM}_{2.5}$ is $101.15 \mu \mathrm{g} / \mathrm{m}^{3}$ [47], which is nearly three times higher than the standard concentration of $\mathrm{PM}_{2.5}\left(35 \mu \mathrm{g} / \mathrm{m}^{3}\right)$. In response to the severe air pollution, authorities in Beijing released detailed and strict criteria for $\mathrm{PM}_{2.5}$ mitigation: a Five-year Clean Air Action Plan in Beijing (2013-2017) has been issued to reduce the concentration of $\mathrm{PM}_{2.5}$ by $25 \%$ or more by 2017 relative to 2012 [48].

The data for $\mathrm{PM}_{2.5}$ emissions in 2010 from 110 sectors are derived from the greenhouse gas-air pollution interactions and synergies (GAINS) model that is developed by the International Institute for Applied Systems Analysis (IIASA). The input-output table for 42 economic sectors in Beijing is provided by Beijing Municipal Bureau of Statistics. To be consistent with the urban I$\mathrm{O}$ table and $\mathrm{PM}_{2.5}$ emission sectors, the urban economy was separated into forty-two economic sectors. To better understand the embodied $\mathrm{PM}_{2.5}$ emission flow within the system and highlight the key sectors with high intensive of $\mathrm{PM}_{2.5}$ emissions, those forty-two economic sectors were then further aggregated into fifteen larger sectors or components. The basic information (area and energy consumption etc.) of the study area is abstracted from China Statistical Yearbook [3]. The other pertinent data can be found in scientific reports or relevant official website [47-49]. 


\subsection{Input-output analysis (IOA)}

Input-output analysis (IOA) has been shown to be a useful topdown method to distribute emissions or energy consumptions to final demand in a consistent framework [50,51]. It was first developed by Leontief $[52,53]$ and further modified to evaluate the environmental impacts or resources [54-56]. This method can be used to distinguish the direct and indirect emissions embodied in trade from interconnected economic sectors and distribute all the $\mathrm{PM}_{2.5}$ emissions triggered by final demand into each sector to reflect the embodied emission flow across sectors [57]. It should be clarified that some pivotal assumptions have been made to set the system boundary and avoid double counting. First, the study is conducted within the administrative boundary of Beijing to examine the sectoral interactions through the economic activities more deeply. Second, those goods and services imported from other regions or countries are assumed to have the same $\mathrm{PM}_{2.5}$ emission coefficient as local products [33].

$x_{i}=\sum_{j=1}^{n} X_{i j}+y_{i}$

where $x_{i}$ is the total economic output of the $i$ th sector; $n$ refers to the number of economic sectors; $X_{i j}$ represents the monetary flows from the $i$ th sector to the $j$ th sector; $y_{i}$ is the final demand of sector $i$.

The technical coefficient matrix $A$ is calculated as:

$A=X_{i j} / x_{j}$

Combining Eqs. (1) and (2), we can get

$x=(I-A)^{-1} y$

where $x$ is the vector of sectoral output; $I$ represents the identity matrix; $y$ refers to a vector of final demand; $(I-A)^{-1}$ is known as the Leontief inverse matrix, which depicts the total production of each sectors required to meet a particular final demand in monetary value.

$\mathrm{PM}_{2.5}$ emission intensity from each sector can be calculated by:

$k_{i}=E_{i} / x_{i}$

where $E_{i}$ stands for the total $\mathrm{PM}_{2.5}$ emissions from sector $i ; k_{i}$ is the $\mathrm{PM}_{2.5}$ emission coefficient which is calculated by total $\mathrm{PM}_{2.5}$ emissions from each sector divided by total output of the corresponding sector. To convert the monetary flow into emissions flow, Eqs. (3) and (4) should be combined:

$E_{i}=k_{i}(I-A)^{-1} y$

By extending Eq. (5), we can get:

$E_{i}=\left(k_{i} y+k_{i} A y\right)+\left(k_{i} A^{2} y+k_{i} A^{3} y+\cdots\right)$

Then, the direct and indirect $\mathrm{PM}_{2.5}$ emissions can be calculated as:

$D_{P M}=k(I+A) y$

$I_{P M}=k(I-A)^{-1} y-D_{P M}$

where $D_{P M}$ and $I_{P M}$ represent direct and indirect $\mathrm{PM}_{2.5}$ emissions, respectively. Thus, the amount of direct and indirect $\mathrm{PM}_{2.5}$ emissions from each sector can be separated from the total emissions. Accordingly, who is the beneficiary and who is the sufferer become apparent.

\subsection{Ecological network analysis (ENA)}

Ecological network analysis (ENA) is adopted to present the degree of each economic sector controlled by other sectors in terms of the embodied $\mathrm{PM}_{2.5}$ emissions and to find one or several sectors playing the dominant role from a systematic perspective [58]. More detailed calculation of the equation in this analysis can be found in previous studies [59,60]. It is based on pair-wise integral flows that measure the level of control and dependence of each sector [61]. The network-based control differences and ratio are determined by flow-forward and flow-backward transfer efficiencies, $G, G^{\prime}$, and integral flow matrices, $N$ and $N^{\prime}$ [62].

$G=g_{i j}=f_{i j} / T_{j}$

$G^{\prime}=g_{i j}^{\prime}=f_{i j} / T_{i}$

$N=(I-G)^{-1}$

$N^{\prime}=\left(I-G^{\prime}\right)^{-1}$

where $g_{i j}$ is the transfer efficiency from sector $j$ to sector $i$; $f_{i j}$ refers to the embodied $\mathrm{PM}_{2.5}$ emissions flow from sector $j$ to sector $i ; T_{j}$ represents the total outflow from sector $j ; N$ is the integral slow matrices which combined the direct and indirect $\mathrm{PM}_{2.5}$ emissions.

System-based comparisons of the fractional transfer values are revealed by the control difference:

$C D_{i j}=\eta_{i j}-\eta_{j i}$

where $C D_{i j}$ is control difference between sector $i$ and sector $j$. If $C D_{i j}$ is a positive value, it represents that sector $i$ is depend on sector $j$, if not, then sector $i$ controls sector $j . \eta_{i j}$ is fractional transfer coefficients which is calculated by integral flow from sector $i$ to sector $j$ divided by total emission from sector $i$.

Pair-wise sectoral comparisons of the fractional transfer values can be easily interpreted by the control ratio $\left(C R_{i j}\right)$ :

$C R_{i j}=\left(\eta_{i j}-\eta_{j i}\right) / \max \left(\eta_{i j}, \eta_{j i}\right)$

$C R$ is a non-dimensional matrix with an absolute value between zero and one. If the absolute value of $C R$ approaches to 1 , the direction of flow between these two sectors is definite, namely, the dominant position and subordinate position of the pair-wise sectors is easy to distinguish; if the absolute value turns the other way around, the connection of pair-wise sectoral relationship becomes weak, namely, the direction of the flow from one sector to another is indistinct as the mutual flows are offset by each other.

Since the magnitudes of the control differences $C D_{i j}$ are coming from the consistent system and all additive. Thus, system control vector that represents the level of hierarchy of each sector within the system can be calculated by summing the rows of the control difference matrix:

$S C_{j}=\sum_{k=1}^{n} C D_{k j}, \quad j=1,2, \ldots, n$

where $S C_{j}$ is a vector of system control. This equation reveals each sector's magnitude of control weighting among a system. Therefore, if the value of $S C_{j}$ is positive, the corresponding sector $j$ controls the whole system (remaining sectors combined, $k \neq j$ ); to the contrary, a negative $S C_{j}$ value represents that sector $j$ is controlled by the system (remaining sectors combined, $k \neq j$ ). All $S C_{j}$ added together equal to zero due to the balance of the whole system.

\section{Results}

From Fig. 1, it is obvious that "Residential Services" ranks fist as the major contributor to the direct $\mathrm{PM}_{2.5}$ emissions with $32.6 \mathrm{kt} / \mathrm{y}$. It should be mentioned that the raw data of $\mathrm{PM}_{2.5}$ emissions from "Residential Services" are mainly caused by the combustion of hard coal, agricultural residuals, and fuelwood in cooking and heating 


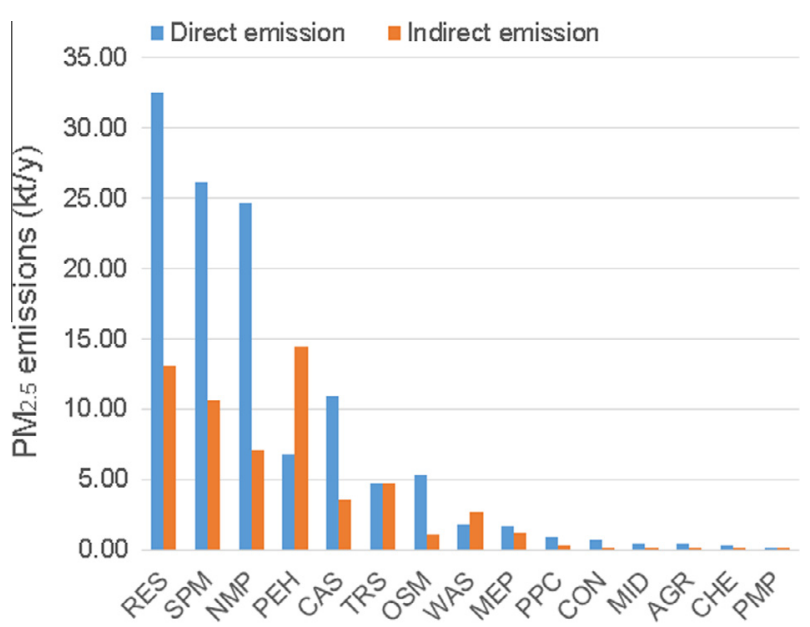

Fig. 1. Direct \& indirect $\mathrm{PM}_{2.5}$ emission from 15 aggregated sectors. Note: Agriculture (AGR), Mining \& Dressing (MID), Papermaking \& Printing (PMP), Petroleum Processing \& Coking (PPC), Chemicals (CHE), Nonmetal Mineral Products (NMP), Smelting \& Pressing of Metals (SPM), Metal Products (MEP), Ordinary \& Special Machinery \& Equipment (OSM), Waste (WAS), Production \& Supply of Electricity \& Heat (PEH), Construction (CON), Transportation \& Storage (TRS), Catering Services (CAS), Residential Services (RES).

stoves. "Smelting \& Pressing of Metals" and "Nonmetal Mineral Products", with $26.1 \mathrm{kt} / \mathrm{y}$ and $24.7 \mathrm{kt} / \mathrm{y}$ direct $\mathrm{PM}_{2.5}$ emissions, respectively, rank second and third. In comparison, the direct $\mathrm{PM}_{2.5}$ emissions from other socioeconomic activities, such as "Agriculture" (0.4 kt/y), "Chemicals" (0.3 kt/y) and "Papermaking \& Printing" $(0.1 \mathrm{kt} / \mathrm{y})$, are negligible. Meanwhile, the total amount of $\mathrm{PM}_{2.5}$ emissions (including both direct and indirect emission) from these three sectors are quite small, only accounting for $0.62 \%$ of the total emission from fifteen aggregated sectors. As for "Production \& Supply of Electricity \& Heat" sector, the indirect emission of $\mathrm{PM}_{2.5}$ with $14.4 \mathrm{kt} / \mathrm{y}$ is extraordinarily higher than the other sectors, almost twice as much as its direct emission.

Fig. 2 shows the proportions of direct and indirect $\mathrm{PM}_{2.5}$ emission from 15 aggregated sectors. Overall, within the whole socioeconomic system, indirect emissions account for $33.6 \%$ of the total $\mathrm{PM}_{2.5}$ emissions. This includes all emissions physically generated in one sector then allocated to downstream sector's production or consumption. The sector having the largest proportion of indirect emissions is "Production \& Supply of Electricity \& Heat" with

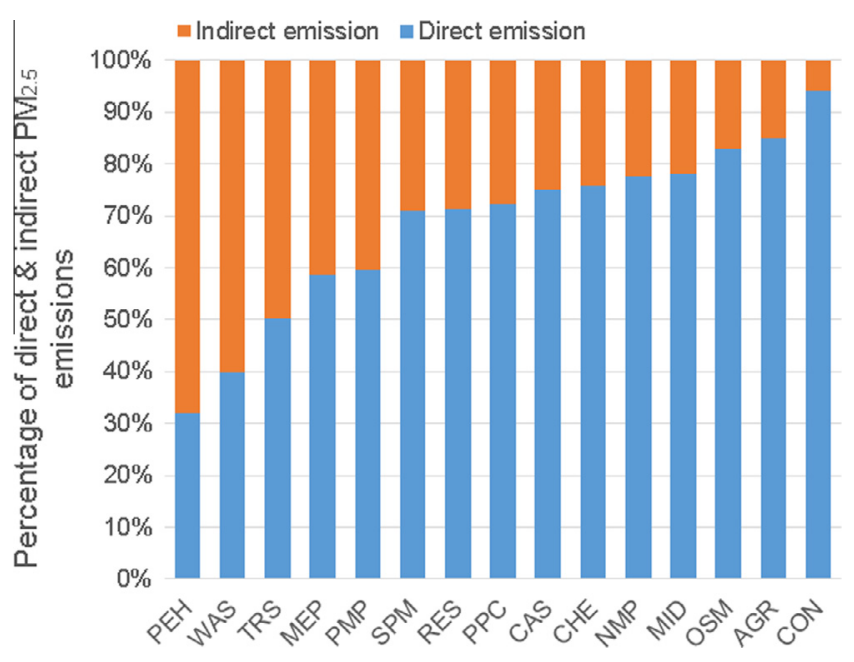

Fig. 2. Comparison of percentage of direct and indirect $\mathrm{PM}_{2.5}$ emission from 15 aggregated sectors.
$68 \%$, which indicates that most of the goods produced in this sector are consumed in other sectors. The $\mathrm{PM}_{2.5}$ emissions from "Waste" sector are primarily coming from open burning of residential waste according to the original data. Fig. 2 illustrates that $40 \%$ of $\mathrm{PM}_{2.5}$ emissions from "Waste" is direct emission. It can be interpreted that, after waste incineration, waste residue with three fifth of embodied $\mathrm{PM}_{2.5}$ emissions is reused or recycled by other sectors (e.g., compost). The proportion of indirect emissions from "Construction" sector is 6\%, ranking the least. The primary cause of $\mathrm{PM}_{2.5}$ emissions is fugitive dust and no data for fuel use in this sector.

The control ratio condition of each sector is illustrated in Fig. 3. The value of control ratio from "Metal Products" (matrix column) to "Agriculture" (matrix row) is 0.98 , which indicates that the former sector is in a position of overwhelming dominance of pairwise control relationship. The "Nonmetal Mineral Products" controls "Agriculture" with a magnitude of 0.05 . It means that the pair-wise linkage between these two sectors is very weak. With all the positive value above 0.5 , "Smelting \& Pressing of Metals" is shown to overwhelmingly control the remaining sectors except "Waste". The control ratio from "Catering Services" to other sectors except "Mining \& Dressing" $(0.10)$ is ranging from -0.17 to -0.95 , indicating that "Catering Services" passively receives embodied emissions due to imports from other sectors and rarely exports to others.

Except for the dominance of sectors, control ratio can also identify the strong/weak pathways. The pair-wise relationship of control ratio with a magnitude above 0.5 or below -0.5 can be defined as strong connection, such as, SPM-CHE, RES-NMP and PEH-AGR. Similarly, weak linkages between pair-wise sectors exist with the value of control ratio ranging from -0.5 to 0.5 , e.g., RESWAS, NMP-MID and OSM-CHE.

Fig. 4 describes the control difference of each sector. By recognizing the color of "Agriculture" sector, it is the major embodied $\mathrm{PM}_{2.5}$ emissions receiver. Nearly every pair-wise sectoral relationship are dependent on the other sectors. The relationship between "Chemistry" and the majority of sectors fluctuated between -0.01

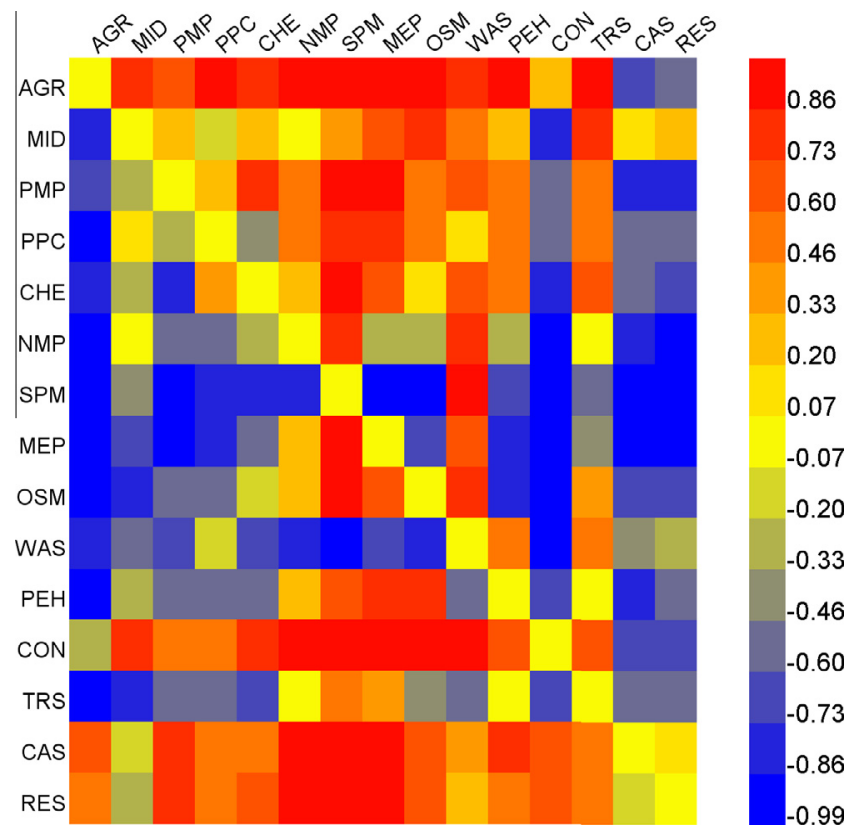

Fig. 3. Pair-wise control/dependence ratios between each sector. Note: The progression of control ratio relationship is from column to rows. Positive numbers represent the dominant position, negative numbers refer to the subordinate position. 


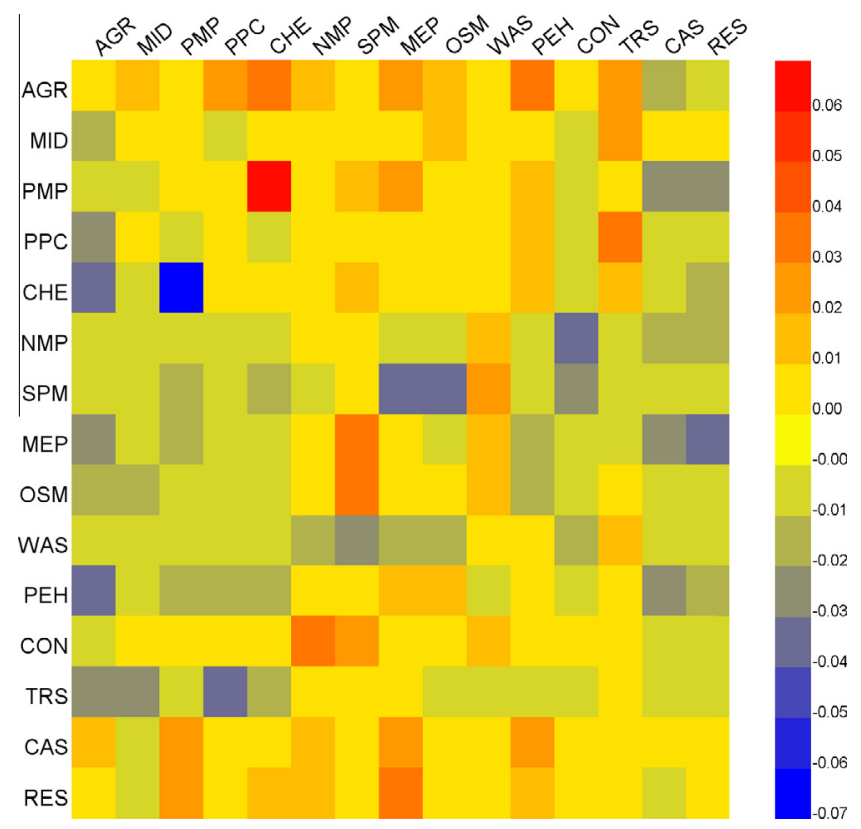

Fig. 4. Pair-wise control/dependence differences between 15 economic sectors. Note: Positive numbers represent the control relationship, negative numbers refer to the dependent relationship. The control/dependence relationships of each sector are illustrated from the column to the row (e.g., CHE sector has strong control over PMP sector and PMP sector is largely dependent on CHE sector).

and 0.01, while "Papermaking \& Printing" and "Agriculture" are exceptions. The observation can be interpreted that the pathways from "Chemistry" to those two sectors are strongly connected and the "Chemistry" sector has strong control power over these two sectors in the embodied emission network. "Residential Services", "Transportation \& Storage", and "Catering Services" are the sectors that have dependent positions among the pair-wise sectoral comparison. These three sectors are closely related to the service industry. Meanwhile, "Mining \& Dressing”, "Petroleum Processing \& Coking", and "Metal Products" are sectors that showed a neutral relationship when connecting with other sectors, which means the magnitudes of control level between these sectors and the other sectors are quite close to each other.

The dependence intensity of the 15 aggregated sectors based on the result of system control matrix is presented in Fig. 5. From a systematic perspective, the control intensity of "Smelting \& Pressing of Metals" is the largest, followed by "Metal Products" and "Nonmetal Mineral Products". The results indicate that those sectors related to industrial production are the dominant controllers of embodied emission network and driving the embodied $\mathrm{PM}_{2.5}$ emissions in the whole system. As for the dependents, the value of service sectors, including "Transportation", "Residential Services", and "Catering Services", are below the horizon line, which indicates that service industry is controlled by other sectors in the embodied emission network. "Agriculture" with control level of -0.2 stays in the position of the major dependent of the network. System control of "Production \& Supply of Electricity \& Heat", “Ordinary \& Special Machinery \& Equipment" and "Petroleum Processing \& Coking" fluctuated from -0.05 to 0.05 , indicating these sectors' positions (control or dependent) among the whole system are not notable.

\section{Discussions and conclusions}

The production-based $\mathrm{PM}_{2.5}$ emissions accounting is a direct way to identify the contributors of different production processes, while consumption-based analysis provides an alternative approach to explore the consumer's impact on $\mathrm{PM}_{2.5}$ emissions. Embodied emission, including direct and indirect emissions, is based on a holistic view that is the combination of productionbased and consumption-based perspective. Direct emission stands for $\mathrm{PM}_{2.5}$ emissions physically produced from resources that are directly devoted to on-site production process for the same socioeconomic activity, while indirect emission represents emissions generated during the production of goods that are consumed by the other sectors. Referring to the raw data of $\mathrm{PM}_{2.5}$ emissions inventories, the direct emissions from "Residential Services" ranking first among the fifteen aggregated sectors are due to the inefficiency of coal combustion from heating stoves and cooking stoves. It was reported that unreasonable energy structure (mainly coal and petroleum) is the main cause of air pollution and the major contributor of $\mathrm{PM}_{2.5}$ emissions based on coal combustion is not coming from power plant but from residential heating or cooking located in suburban areas [63]. Supportive information can be found in previous studies, Lei et al. [9] proved that residential sector is the largest contributor of $\mathrm{PM}_{2.5}$ emissions and $80 \%$ of $\mathrm{PM}_{2.5}$ emissions in this sector come from fuel combustion in indigenous stoves. Similar results can be found in the report conducted by Guan and Liu [49]. It shows that $32 \%$ of primary $\mathrm{PM}_{2.5}$ emissions

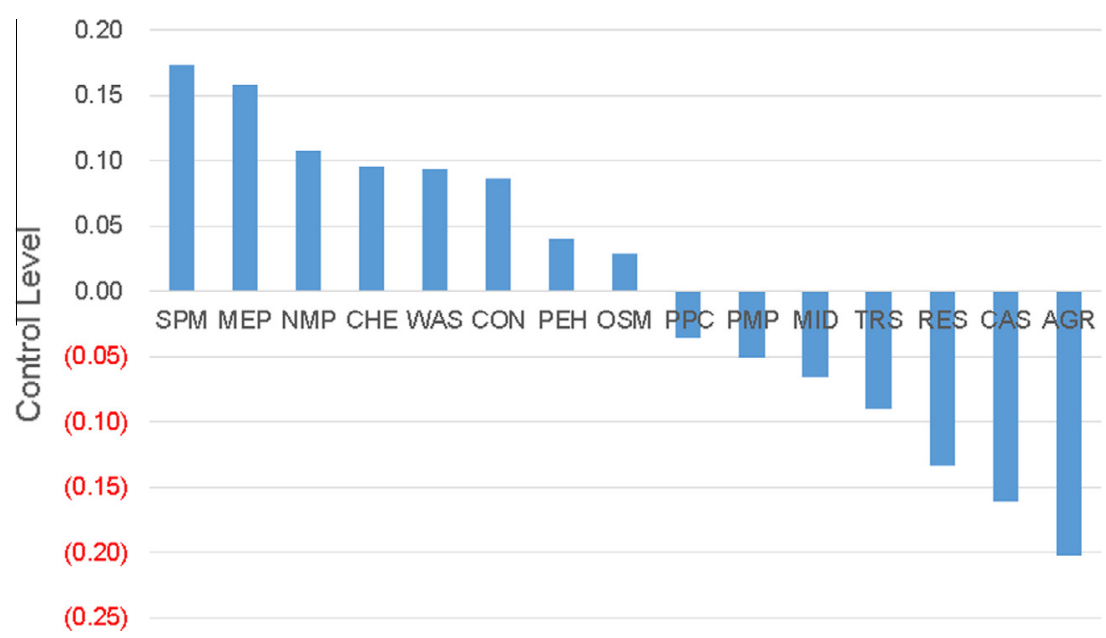

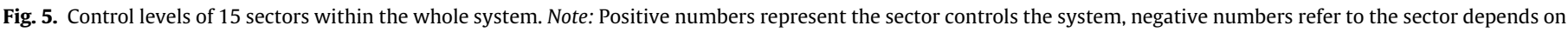
the rest of the sectors. 
is from "Residential and Commercial Services" and $49 \%$ of $\mathrm{PM}_{2.5}$ emissions is from "Industrial Process". In this study, due to the disaggregation of "Industrial Process" (including "Smelting \& Pressing of Metals" and "Metal Products" etc.), the "Residential Services" became the major contributor of $\mathrm{PM}_{2.5}$ emissions. According to the results, direct $\mathrm{PM}_{2.5}$ emissions from "Smelting \& Pressing of Metals" and "Nonmetal Mineral Products" rank second and third. It is because those sectors are related to the high $\mathrm{PM}_{2.5}$ intensity industrial processes. Normally, the indirect emissions from these two sectors are related to the metal and nonmetal mineral products which are purchased by other sectors. About two thirds of total $\mathrm{PM}_{2.5}$ emissions from "Production \& Supply of Electricity \& Heat" are indirect emissions which is relatively high compared to other sectors. This is because a large amount of $\mathrm{PM}_{2.5}$ emissions were produced during the production of this sector and those pollutant intensive commodities were then exported to the others to meet their final demand. "Agriculture" only has 0.48 kt PM 2.5 emissions in 2010, which probably resulted from the booming industry of service and the rapid expansion of urban area. "Construction", mainly refer to the urbanization and infrastructure construction, can cause disturbance of the surface soil on regional scale which contribute large percent of its direct emissions.

Moreover, ENA provides a systematic pattern through the link of embodied $\mathrm{PM}_{2.5}$ emission flows with each socioeconomic activity. By exploring the sectors' interactions and network configuration, the influence hidden in the network can be uncovered from a holistic perspective. The control and dependence capacities of the network present another facet of the emissions flows via socioeconomic activities, which illustrate the mutual relationships between pair-wise sectors and uncover the dominant sector(s) and dependent sector(s) that might be helpful to formulate polices of alleviating the air pollution. In Beijing, current policies for air pollution abatement focus on reducing the total amount of $\mathrm{PM}_{2.5}$ emissions, while the inner interactions and linkages of embodied emissions circulation throughout the socioeconomic system are largely ignored. The control ratio calculation based on ENA can represent the strength of the disparity between the two fractional open-loop control magnitudes [60]. Each value from the control ratio matrix compares the input and output transfer weights between two sectors. Regarding the results based on ENA, the control ratio condition of pair-wise sectors with positive and negative numbers reveals the dominant and subordinate status of each sector. The magnitude of control ratio presents the strong and weak linkages of pair-wise sectors. The results based on ENA show that sectors related to production and supply of material are in the top three controlling sectors, which means that these sectors are major contributors in the embodied $\mathrm{PM}_{2.5}$ system in Beijing. It is because their production process contains high intensive $\mathrm{PM}_{2.5}$ emissions embodied in the products and transported to other sectors. Results of ENA suggest ways to optimize and control the flows of materials and energy for regional air pollution management.

According to the results based on IOA, indirect $\mathrm{PM}_{2.5}$ emissions account for a large proportion of total emissions that have been neglected while formulating policies to address air pollution. Therefore, considering both direct and indirect emission from each sector, while distributing the reduction targets of $\mathrm{PM}_{2.5}$ emissions, is reasonable and impartial. Sectors with high direct emissions, like "Residential Services" and "Smelting \& Pressing of Metals", are expected to improve the efficiency of fuel combustion and adopt effective control technology. Meanwhile, those with high indirect emissions, like "Production \& Supply of Electricity \& Heat", may require added charges to reflect accurately the cost to get people to economize on such commodities and to produce goods in accordance with the final demands to avoid wasting energy.

"Smelting \& Pressing of Metals", "Metal Products" and "Nonmetal Mineral Products" are the dominant sectors of embodied
$\mathrm{PM}_{2.5}$ emissions, which reveals that material productions should set strict regulations to reduce the $\mathrm{PM}_{2.5}$ emissions. Those sectors are obligated to not only apply advanced zero or low emission technologies, but also adopt a quota system when producing products. The pair-wise control level ranging from negative value to positive value implies that each sector exerts a certain degree of influence (dominance or dependence) on other sectors. The strong pathways, such as SPM-RES, NMP-RES and MEP-RES, indicate that embodied $\mathrm{PM}_{2.5}$ emissions flows between the pair-wise sectors are almost completely controlled by one side and their flow directions are fixed. For example, "Smelting \& Pressing of Metals" is the main controller of "Residential Services" because there is a strong input of $\mathrm{PM}_{2.5}$ intensive products from "Smelting \& Pressing of Metals" to "Residential Services". While formulating sensible policy to reduce the $\mathrm{PM}_{2.5}$ emissions, it is necessary to tackle this issue from a systematic perspective by improving the technologies related to low $\mathrm{PM}_{2.5}$ emissions in dominant sectors (e.g., "Smelting \& Pressing of Metals", "Nonmetal Mineral Products" and "Metal Products") and increasing the utilization of products that were produced in these sectors and then consumed in "Residential Services". Therefore, indirect interactions between socioeconomic activities are vital and should be considered to mitigate the air pollution.

There is still more room to explore the inner structure of economic sectors and to optimize the energy structure in terms of $\mathrm{PM}_{2.5-}$ emissions. ENA is a useful tool to detect the static interdependence between different sectors connected by direct and indirect trade flows, but it is insufficient to simulate dynamic embodied emission system. A national-level database of different cities in China would enable comparison of regional discrepancy based on material/energy balance network. However, this work is a first step toward establishing such a network based on ENA to explore the mechanism and pathways of embodied emission within the socioeconomic system in China.

\section{Acknowledgments}

This work was supported by the Fund for Innovative Research Group of the National Natural Science Foundation of China (No. 51421065), National Natural Science Foundation of China (Nos. 71573021, No. 41511140123), Specialized Research Fund for the Doctoral Program of Higher Education of China (No. 20130003110027), and 2015 Young Scientists Summer Program (YSSP) at the International Institute for Applied Systems Analysis (IIASA).

\section{References}

[1] Liu G, Yang Z, Chen B, Zhang Y, Su M, Ulgiati S. Prevention and control policy analysis for energy-related regional pollution management in China. Appl Energy 2015.

[2] Zhang S, Worrell E, Crijns-Graus W. Evaluating co-benefits of energy efficiency and air pollution abatement in China's cement industry. Appl Energy 2015; $147: 192-213$

[3] China Statistical Yearbook 2003. National bureau of statistics of China. Beijing: China Statistics Press; 2013.

[4] Fairley P. China's coal future. Technol Rev 2007;110(1):56-61.

[5] Uchiyama S, Hasegawa S. Investigation of a long-term sampling period for monitoring volatile organic compounds in ambient air. Environ Sci Technol 2000;34(21):4656-61.

[6] Zheng M, Salmon LG, Schauer JJ, Zeng L, Kiang CS, Zhang Y, et al. Seasonal trends in $\mathrm{PM}_{2.5}$ source contributions in Beijing, China. Atmos Environ 2005;39 (22):3967-76.

[7] Tao J, Gao J, Zhang L, Zhang R, Che H, Zhang Z, et al. $\mathrm{PM}_{2.5}$ pollution in a megacity of southwest China: source apportionment and implication. Atmos Chem Phys 2014;14(16):8679-99.

[8] Zhang Q, Streets DG, He K, Klimont Z. Major components of China's anthropogenic primary particulate emissions. Environ Res Lett 2007;2(4). 045027.

[9] Lei Y, Zhang Q He KB, Streets DG. Primary anthropogenic aerosol emission trends for China, 1990-2005. Atmos Chem Phys 2011;11(3):931-54. 
[10] Zhang R, Jing J, Tao J, Hsu SC, Wang G, Cao J, et al. Chemical characterization and source apportionment of $\mathrm{PM}_{2.5}$ in Beijing: seasonal perspective. Atmos Chem Phys 2013;13(14):7053-74.

[11] Guan D, Su X, Zhang Q, Peters GP, Liu Z, Lei Y, et al. The socioeconomic drivers of China's primary $\mathrm{PM}_{2}{ }_{5}$ emissions. Environ Res Lett 2014;9(2). 024010.

[12] Guan D, Lin J, Davis SJ, Pan D, He K, Wang C, et al. Reply to Lopez et al.: consumption-based accounting helps mitigate global air pollution. Proc Natl Acad Sci 2014;111(26). E2631-E2631.

[13] Streets DG, Yu C, Bergin MH, Wang X, Carmichael GR. Modeling study of air pollution due to the manufacture of export goods in China's Pearl River Delta. Environ Sci Technol 2006;40(7):2099-107.

[14] Yang S, Chen B, Fath B. Trans-boundary total suspended particulate matter (TSPM) in urban ecosystems. Ecol Model 2015;318:59-63.

[15] Zhao HY, Zhang Q, Guan DB, Davis SJ, Liu Z, Huo H, et al. Assessment of China's virtual air pollution transport embodied in trade by using a consumptionbased emission inventory. Atmos Chem Phys 2015;15(10):5443-56.

[16] Huo H, Zhang Q, Guan D, Su X, Zhao H, He K. Examining air pollution in China using production-and consumption-based emissions accounting approaches. Environ Sci Technol 2014:48(24):14139-47.

[17] Lin J, Pan D, Davis SJ, Zhang Q, He K, Wang C, et al. China's international trade and air pollution in the United States. Proc Natl Acad Sci 2014;111 (5):1736-41.

[18] Kondo Y, Moriguchi Y, Shimizu H. $\mathrm{CO}_{2}$ emissions in Japan: influences of imports and exports. Appl Energy 1998;59(2):163-74.

[19] Li JS, Xia XH, Chen GQ Alsaedi A, Hayat T. Optimal embodied energy abatement strategy for Beijing economy: based on a three-scale input-output analysis. Renew Sustain Energy Rev 2016;53:1602-10.

[20] Wiedmann T, Minx J. A definition of 'carbon footprint'. Ecol Econ Res Trends 2008;1:1-11.

[21] Costanza R. Embodied energy and economic valuation. Science 1980;210 (4475):1219-24.

[22] Feng K, Chapagain A, Suh S, Pfister S, Hubacek K. Comparison of bottom-up and top-down approaches to calculating the water footprints of nations. Econ Syst Res 2011;23(4):371-85

[23] Proops JLR. Input-output analysis and energy intensities: a comparison of some methodologies. Appl Math Model 1977;1(4):181-6.

[24] Leontief W, Ford D. Air pollution and the economic structure: empirical results of input-output computations. In: Input-output techniques: proceedings of the fifth international conference on input-output techniques. Amsterdam: North-Holland Publishing Company; 1972. p. 9-30.

[25] Miller RE, Blair PD. Input-output analysis: foundations and extensions. Cambridge University Press; 2009.

[26] Leontief W. Input-output economics. Oxford University Press; 1986.

[27] Li JS, Chen GQ, Hayat T, Alsaedi A. Mercury emissions by Beijing's fossil energy consumption: based on environmentally extended input-output analysis. Renew Sustain Energy Rev 2015;41:1167-75.

[28] Leontief W, Morgan A, Polenske K, Simpson D, Tower E. The economic impactindustrial and regional-of an arms cut. Rev Econ Statist 1965;47(3):217-41.

[29] Leontief W. Environmental repercussions and the economic structure: an input-output approach. Rev Econ Statist 1970;52(3):262-71.

[30] Meng J, Liu J, Xu Y, Tao S. Tracing primary $\mathrm{PM}_{2.5}$ emissions via Chinese supply chains. Environ Res Lett 2015;10(5). 054005.

[31] Meng J, Liu J, Guo S, Huang Y, Tao S. The impact of domestic and foreign trade on energy-related PM emissions in Beijing. Appl Energy 2015.

[32] Hartman LM. The input-output model and regional water management. J Farm Econ 1965;47(5):1583-91

[33] Wiedmann T. A review of recent multi-region input-output models used for consumption-based emission and resource accounting. Ecol Econ 2009;69 (2):211-22.

[34] Nässén J, Holmberg J, Wadeskog A, Nyman M. Direct and indirect energy use and carbon emissions in the production phase of buildings: an input-output analysis. Energy 2007;32(9):1593-602.

[35] Fang D, Chen B. Ecological network analysis for a virtual water network-a case study of the Heihe River Basin. Environ Sci Technol 2015;49(11):6722-30.

[36] Hannon B. The structure of ecosystems. J Theor Biol 1973;41(3):535-46.

[37] Jørgensen SE, Xu L, Costanza R. Handbook of ecological indicators for assessment of ecosystem health. CRC Press; 2010.
[38] Ulanowicz RE, Holt RD, Barfield M. Limits on ecosystem trophic complexity: insights from ecological network analysis. Ecol Lett 2014;17(2):127-36.

[39] Patten BC. Systems approach to the concept of environment. Ohio J Sci 1978;78:206-22.

[40] Patten BC, Auble GT. System theory of the ecological niche. Am Nat 1981:893-922.

[41] Borrett SR, Whipple SJ, Patten BC, Christian RR. Indirect effects and distributed control in ecosystems: temporal variation of indirect effects in a sevencompartment model of nitrogen flow in the Neuse River Estuary, USA-time series analysis. Ecol Model 2006;194(1):178-88.

[42] Chen S, Chen B, Fath BD. Ecological risk assessment on the system scale: a review of state-of-the-art models and future perspectives. Ecol Model 2013;250:25-33.

[43] Zhang Y, Li S, Fath BD, Yang Z, Yang N. Analysis of an urban energy metabolic system: comparison of simple and complex model results. Ecol Model 2011:223(1):14-9.

[44] Chen S, Chen B. Network environ perspective for urban metabolism and carbon emissions: a case study of Vienna, Austria. Environ Sci Technol 2012;46 (8):4498-506.

[45] Schramski JR, Gattie DK, Patten BC, Borrett SR, Fath BD, Whipple SJ. Indirect effects and distributed control in ecosystems: distributed control in the environ networks of a seven-compartment model of nitrogen flow in the Neuse River Estuary, USA-Time series analysis. Ecol Model 2007;206:18-30.

[46] Beijing Statistical Yearbook 2014. Beijing: China Statistics Press; 2014.

[47] Embassy of the United States. <http://www.stateair.net/web/historical/1/1. html>.

[48] Xinhua Net. A Five-year Clean Air Action Plan (2013-2017) <http://www.bj. xinhuanet.com/bjuw/2013-09/13/c 117351459.htm> [in Chinese, accessed 15.08.15].

[49] Guan DB, Liu Z. Truth of Haze: source apportionment and reduction strategies analysis of $\mathrm{PM}_{2.5}$ in Jing-Jin-Ji district. Green Peace; 2013.

[50] Yu Y, Feng K, Hubacek K. Tele-connecting local consumption to global land use. Global Environ Change 2013;23(5):1178-86.

[51] Feng K, Siu YL, Guan D, Hubacek K. Assessing regional virtual water flows and water footprints in the Yellow River Basin, China: a consumption based approach. Appl Geogr 2012;32(2):691-701.

[52] Leontief W. Quantitative input and output relations in the economic systems of the United States. Rev Econ Statist 1936;18(3):105-25.

[53] Leontief W. Interrelation of prices, output, savings, and investment. Rev Econ Statist 1937:19(3):109-32.

[54] Manne AS, Richels RG. $\mathrm{CO}_{2}$ emission limits: an economic cost analysis for the USA. Energy J 1990;11(2):51-74.

[55] Chen S, Chen B. Urban energy consumption: different insights from energy flow analysis, input-output analysis and ecological network analysis. Appl Energy 2015;138:99-107.

[56] Lenzen M. Primary energy and greenhouse gases embodied in Australian final consumption: an input-output analysis. Energy Policy 1998;26(6):495-506.

[57] Miller R, Blair P. Input-output analysis: foundations and extensions. Englewood Cliffs: Prentice-Hall; 1985.

[58] Gattie DK, Schramski JR, Borrett SR, Patten BC, Bata SA, Whipple SJ. Indirect effects and distributed control in ecosystems: network environ analysis of a seven-compartment model of nitrogen flow in the Neuse River Estuary, USAsteady-state analysis. Ecol Model 2006;194(1):162-77.

[59] Fath BD. Distributed control in ecological networks. Ecol Model 2004;179 (2):235-45.

[60] Schramski JR, Gattie DK, Patten BC, Borrett SR, Fath BD, Thomas CR, et al. Indirect effects and distributed control in ecosystems: Distributed control in the environ networks of a seven-compartment model of nitrogen flow in the Neuse River Estuary, USA-Steady-state analysis. Ecol Model 2006;194 (1):189-201.

[61] Ulanowicz RE. Mass and energy flow in closed ecosystems. J Theor Biol 1972;34(2):239-53.

[62] Fath BD, Patten BC. Review of the foundations of network environ analysis. Ecosystems 1999;2:167-79.

[63] Peng YC, Xu Y, Zeng F. Coal combustion from residents is more hazardous than that from power plant. China Electric Power News Office, April 11th, 2014, 002 . 